\title{
Olhos desnudos: Uma tradução intersemiótica da composição buarquiana Olhos nos Olhos
}

\author{
Janaina Santos Silva Soggia ${ }^{11}$
}

\section{Resumo}

O artigo apresenta uma análise intersemiótica da composição buarquiana Olhos nos olhos a partir da recriação literária Olhos nus: olhos, feita pelo escritor moçambicano Mia Couto no livro Essa história está diferente: Dez contos para canções de Chico Buarque (2010), sob organização de Ronaldo Bressane. O objetivo desta análise é traçar o caminho da transmutação do olhar das personagens centrais, João Rosa e Clarice, em decorrência de seu desenlace afetivo-amoroso.

Palavras-chave: Chico Buarque. Mia Couto. Intertextualidade. Recriação. Tradução Intersemiótica. Olhos.

\begin{abstract}
The article presents a intersemiotic analysis on the buarquiana composition Olhos nos olhos from the literary recreation Olhos nus: olhos writen by the Mozambican writer Mia Couto in the book Essa história está diferente: Dez contos para canções de Chico Buarque (2010), organized by Ronaldo Bressane. The objective of this analysis is to trace the transmutation path of the central characters' look - João Rosa and Clarice - due to their affective-loving outcome.
\end{abstract}

Keywords: Chico Buarque. Mia Couto. Intertextuality. Recreation. Translation Intersemiotic. Eyes.

"Os olhos são a janela da alma, o espelho do mundo."
Leonardo da Vinci
"A paixão é um fio de chuva em vidro de janela."
Mia Couto

Introdução

\section{OLHOS NUS: OLHOS: UMA TRADUÇÃO INTERSEMIÓTICA}

O conto selecionado para análise foi extraído da obra Essa história está diferente: dez contos para canções de Chico Buarque, organizada por Ronaldo Bressane, cujo objetivo é estabelecer uma recriação literária a partir das letras do compositor carioca. O

\footnotetext{
${ }^{1}$ SOGGIA, Janaina Santos Silva. Mestranda pela Pontifícia Universidade Católica de São Paulo - Brasil. Email: profa.janasoggia@gmail.com.

Revista Leitura V.2 no 56 - jul/dez 2015 - Número regular - Autor/a: Janaina Santos Silva Soggia p. $88-102$.
} 
organizador atesta "o desafio proposto aos dez autores de Essa história está diferente: olhar para as canções de Chico Buarque como inspiração e delírio, como uma cama armada para a ficção deitar e rolar”. (BRESSANE, 2010, contracapa).

A partir dessa premissa, argumentamos, neste trabalho, que a recriação literária realizada pelo escritor moçambicano, Mia Couto, em Olhos nus: olhos pode ser vista como uma tradução intersemiótica da composição buarquiana Olhos nos olhos, valendo-nos para tal do conceito de tradução intersemiótica primeiramente postulado pelo linguista russo, Roman Jakobson, em "Aspectos linguísticos da tradução": “A tradução intersemiótica ou transmutação consiste na interpretação de signos verbais por meio de sistemas de signos não verbais" (JAKOBSON, 1969, p. 65). Tal conceito foi posteriormente expandido por Julio Plaza (1987) para incluir processos também na direção oposta: de sistemas não verbais para verbais.

Essa transmutação ou tradução intersemiótica será evidenciada na recriação literária de Mia Couto logo na inusitada transformação do título: de Olhos nos olhos (no original buarquiano), para Olhos nus: olhos. Abrindo, com isso, uma série de novas ressignificações. A simples troca da contração "nos" para o adjetivo "nus" demonstra que "qualquer signo pode ser traduzido num outro signo em que ele se nos apresenta mais plenamente desenvolvido e mais exato" (JAKOBSON, 1969, p. 66-67).

Mia Couto ao transmutar a perspectiva inicial da letra buarquiana, propõe uma entrada em seu texto que acompanhará o desenho de todo o enredo recriado. O dilema do olhar será uma peça-chave na elaboração sígnica da tradução literária. No decorrer da trama, os olhos das personagens sofrerão expressivas mudanças que culminarão no desnude do olhar, olhos que quase cegam diante da perda e da frustração amorosa.

O trocadilho existente na apresentação do texto de chegada - Olhos nus: olhos recapitula uma discussão levantada pelo semioticista russo, quando atesta a impossibilidade de se traduzir a poesia, devendo-se, portanto, transpô-la criativamente, transmutando-a para o novo sistema de signos:

O trocadilho, ou, para empregar um termo mais erudito e talvez mais preciso, a paranomásia, reina na arte poética; quer esta dominação seja absoluta ou limitada, a poesia, por definição, é intraduzível. Só é possível a transposição criativa: transposição intralingual - de uma forma poética a outra -, a transposição interlingual ou, finalmente, transposição 
intersemiótica - de um sistema de signos para outro, por exemplo, da arte verbal para a música, a dança, o cinema ou a pintura (JAKOBSON, 1969, p. 72).

No que tange ao processo de recriação literária, termo cunhado pelo poeta e tradutor brasileiro Haroldo de Campos (1970), Mia Couto recodifica o texto de partida Olhos nos olhos, composição musical, carregada de lirismo e poesia e transforma-o em uma narrativa literária, mantendo a grafia do português moçambicano e extrapolando a história original. A esse respeito, Marcel Amorim reafirma que um sistema de signos não é transportado de uma língua para outra, mas, sim, recodificado diante da mensagem a ser transmitida, em outro contexto, para outro público e outra cultura. Desse modo a recodificação "é determinada, em grande parte, pelo sistema gramatical da língua de chegada, e, no caso da tradução intersemiótica, do sistema de signos de chegada”. (AMORIM, 2013, p. 17)

Sob esse mesmo prisma, Amorim retoma a análise de Júlio Plaza cujo enfoque afirma que "a tradução cria um original sobre o passado, realizando uma ponte entre pretérito-presente-futuro". (AMORIM, 2013, p. 18). Com base nisso, o conto Olhos nus: olhos pode ser visto como uma retextualização criativa da composição de partida.

Angela Beatriz de Carvalho Faria (UFRJ) em seu artigo "A paixão é um fio de chuva em vidro de janela": "Olhos nus: olhos", de Mia Couto e "Olhos nos olhos", de Chico Buarque (2010), afirma que a recriação do autor moçambicano pode ser configurada como uma nova produção ficcional, porque ressignifica em seu projeto artístico "variações em torno da temática básica: a ruptura amorosa e a fase agônica da separação, o abandono do sujeito feminino pelo masculino, o possível encontro com um outro, o morrer de ciúmes, o triunfo da separação de corrente da perda" (FARIA, 2010, s/p). Essas variações suscitadas por Faria serão desnudadas no decorrer da trama por meio do olhar. Desse modo, as perguntas presentes nas entrelinhas da canção - "Olhos nos olhos / Quero ver o que você faz / Ao sentir que sem você / Eu passo bem demais (...) / Olhos nos olhos / Quero ver o que você diz / Quero ver como suporta me ver tão feliz” (BUARQUE, 1976, s/p) - serão respondidas pela prosa de Mia Couto "ao decifrar, poeticamente, por meio de uma estética da delicadeza, assinalada por insinuações e silêncios, o enigma do olhar e da paixão" (FARIA, 2010, s/p). 
Ao se estabelecer uma base de comparação entre uma composição musical sendo recriada/recodificada/retextualizada no suporte literário, abre-se uma nova discussão sobre a relação entre as diferentes mídias no processo de criação. O termo intermidialidade

refere-se "à fusão, à sobreposição ou ao cruzamento de diferentes campos de estudo como a literatura, a música, as artes visuais, a filosofia, diversas ciências sociais, entre outros” (DARIN, 2015, p. 71).

Nessa perspectiva, analisar a composição buarquiana Olhos nos olhos (1976) em confronto com a recriação literária Olhos nus: olhos (2010) cria um dialogismo intermidiático, no qual transformações/adaptações foram necessárias ao se passar de uma mídia para outra. Daí a razão da proximidade latente entre a tradução intersemiótica e a transposição midiática. Conforme atesta Rajewsky, “O texto ou filme 'original' constitui-se a 'fonte' da recém-formada configuração midiática, cuja formação baseia-se num processo obrigatório de transformação intermidiática específico a uma mídia” (RAJEWSKY, 2012 apud DARIN, 2015, p. 72).

A fim de criar um paralelo entre a obra de partida e a de chegada, cabe remontar a dois conceitos postulados por Gerard Genette (1982), o qual conceitua a obra preexistente como hipotexto e a obra que será recriada como hipertexto: “(...) hipertextos derivados de hipotextos pré-existentes que foram transformados por operações de seleção, ampliação, concretização e efetivação" (DARIN, 2015, p. 73).

Na presente análise, a canção buarquiana será tida como o hipotexto em relação ao texto de chegada, o conto moçambicano, configurado, então, como hipertexto.

\section{O PERCURSo da TRANSPOSiÇão da ObRa MUSiCAl PARA A Mídia LITERÁRIA}

Tomaremos aqui como base a fragmentação da composição buarquiana Olhos nos olhos (1976), em paralelo com a construção da narrativa do autor moçambicano, Mia Couto, Olhos nus: olhos (2010).

Nesse paralelismo fragmentado, duas histórias ocorrerão concomitantemente: a voz do eu-lírico feminino da canção, sendo confrontada com a narrativa das três personagens 
centrais do conto literário: João Rosa, Clarice e Adélia, as quais formam a tríade amorosa que norteará o enredo de Olhos nus: olhos.

Na canção de Buarque, os dois versos iniciais situam a voz feminina sofrendo a dor da perda e aprendendo a recomeçar o viver e o caminhar sem a presença de seu amor. Nesse ponto, tem-se: "Quando você me deixou, meu bem, me disse pra ser feliz e passar bem".

Quanto à composição literária de Mia Couto, a história formulada por Chico Buarque ganha nova roupagem a partir das personagens João Rosa (em homenagem ao célebre escritor mineiro, João Guimarães Rosa), sua ex-esposa, Clarice, homenageando a escritora Clarice Lispector, e sua nova namorada, Adélia, em homenagem à escritora Adélia Prado.

Mia Couto estabelece um dialogismo em sua recriação literária frente à composição musical, ultrapassando-a e superando-a, ao criar doze partes para narrar o enlace tríade de suas personagens já mencionadas. Desse modo, esta análise seguirá o caminho do confronto das partes do conto que dialogam com os trechos da canção, tudo isso seguindo um eixo sintagmático e linear.

A fim de elucidar a intersecção entre a canção e a obra literária, vejamos a tabela abaixo:

\begin{tabular}{|c|c|}
\hline TRECHO & PARTE EQUIVALENTE \\
DA CANÇÃO & DO CONTO LITERÁRIO \\
\hline Quando você me deixou, meu bem & $1^{\mathrm{a}}$ A felicidade não tem alfabeto \\
Me disse pra ser feliz & $2^{\mathrm{a}}$ A adiada visita \\
E passar bem & $3^{\mathrm{a}}$ A tribo dos caçadores \\
\cline { 2 - 2 } Quis morrer de ciúme & $4^{\mathrm{a}}$ Morrer de ciúmes \\
Quase enlouqueci & $5^{\mathrm{a}}$ A furtada lágrima \\
\cline { 2 - 2 } Mas depois como era de costume, obedeci & $6^{\mathrm{a}}$ Um reflexo de mar \\
\cline { 2 - 2 } Quando, talvez, me quiser rever & $7^{\mathrm{a}}$ O telefonema da mãe \\
\cline { 2 - 2 } Já vai me encontrar refeita & $8^{\mathrm{a}}$ A espera de não mais esperar \\
\cline { 2 - 2 } Pode crer & $9^{\mathrm{a}}$ A primeira visita \\
\cline { 2 - 2 } Olhos nos olhos quero ver o que você faz & $10^{\mathrm{a}}$ Livros e colírios \\
\cline { 2 - 2 } Olhos nos olhos quero ver o que você faz & \\
Ao sentir que sem você eu passo bem & \\
demais & $11^{\mathrm{a}}$ O eco da voz \\
E que venho até remoçando & \\
E me pego cantando sem mais nem porquê & \\
(...) & \\
\hline
\end{tabular}

Revista Leitura V.2 no 56 - jul/dez 2015 - Número regular - Autor/a: Janaina Santos Silva Soggia p. $88-102$. 
Olhos nos olhos quero ver o que você diz

Quero ver como suporta

me ver tão feliz

$12^{\mathrm{a}}$ Olhos nos olhos

\section{1) INTERSECÇÃO ENTRE HIPOTEXTO E HIPERTEXTO}

\section{1 - Preâmbulo: Situando as personagens na narrativa}

Quando você me deixou, meu bem Me disse pra ser feliz e passar bem

Chico Buarque

O hipertexto literário inicia situando uma das personagens centrais, João Rosa, em sua nova vida, separado de sua ex-mulher, Clarice e dando partida em uma nova relação amorosa com Adélia. A primeira parte, intitulada A felicidade não tem alfabeto, sucede:

A paixão é um fio de chuva em vidro de janela. Na vida de João Rosa, janelas se sucederam, paixões escoraram sem rosto nem rastro. Mulheres escorreram como apressadas gotas e se neblinaram, aves cruzando o céu. João Rosa não se lembrava de nenhuma das mulheres que amara. Mentira, recordava Clarice (COUTO, 2010, 197).

Diferentemente da canção buarquiana, o conto literário situa o leitor nos três prismas da tríade amorosa, não apenas na voz feminina da mulher deixada. A narrativa se apresenta metaforizando "a paixão é a um fio de chuva em vidro de janela", de modo a estabelecer, logo de início, a relação dos olhos à janela da alma.

A paixão, nesse caso, poderia ser lida como um rastro que luminosidade traz aos olhos. João Rosa se vê "dividido entre o desejo pela nova conquista amorosa, Adélia, e a impossibilidade de esquecer Clarice e, pelo visto, entre a amada com A e a que se inicia com C" (FARIA, 2010, s/p). No conto, as várias mulheres que passaram pela vida de João Rosa não teriam deixado marca, nem rastro. O mesmo, porém, não teria acontecido com Clarice, sua ex-mulher.

Em meio a esse preâmbulo, Adélia, o novo amor de João Rosa, situa o leitor quanto à voracidade do amado por meio de seus olhos. Ela diz: "O que mais me fascina em si não são só os seus olhos negros, esse olhar de confiança absoluta. O que mais me encanta são as suas palavras lindas" (COUTO, 2010, p. 197).

Revista Leitura V.2 no 56 - jul/dez 2015 - Número regular - Autor/a: Janaina Santos Silva Soggia p. $88-102$. 
João Rosa, nesse momento da narrativa, é tido como um homem viril, forte, arrebatador para as mulheres, articulador com as palavras e de olhos negros e confiantes.

$\mathrm{Na}$ segunda parte do conto, A adiada visita, João Rosa evita o confronto com sua ex-esposa, Clarice, há dois meses adiava a visita, mesmo precisando buscar seus pertences mais necessários e imediatos: suas roupas e seus livros. Rosa, por vezes, ia até as proximidades de sua antiga casa, mas não tinha coragem de adentrá-la.

Na janela da papelaria, as gotas de chuva escorriam espessas, primeiro, para depois desabarem subitamente sugadas pela transparência. Rosa fechou os olhos como se quisesse que a chuva escoasse para dentro das pálpebras. E, uma vez mais, voltou a adiar-se (COUTO, 2010, p. 199).

A partir desse momento da narrativa, nota-se que João Rosa não estava tão forte o quanto tencionava demonstrar. De modo que a personagem fecha os olhos "como se quisesse que a chuva escoasse para dentro de suas pálpebras", uma espécie de choro contido, lamento mascarado.

Na terceira parte da trama, chamada de A tribo de caçadores, João Rosa vai ao encontro de seus amigos numa mesa de bar, com a intenção de contar seus grandes feitos, sobretudo, por estar envolvido com Adélia. Esperava, nessa ocasião, os mesmos louros e floreios da trupe masculina: "João Rosa era um caçador triunfante repuxando brilho a bravuras. Como era de esperar, ele trazia um novo troféu. E desta vez não era inventado" (COUTO, 2010, p. 200).

Nesse ponto da narrativa, algo de insólito acontece: os amigos veem em Rosa algo de estranho, uma espécie de máscara:

Os amigos se debruçaram sobre o seu rosto. Não pretendiam apenas ouvir: procuravam em seus olhos o brilho de invejadas glórias e vitórias. (...) Desta vez, porém, os amigos notaram nele uma acabrunhada máscara. (...) A voz era a mesma. Mas havia em seus olhos um cinza tristonho, a gota já escorrida no vidro da janela (COUTO, 2010, p. 200).

Aqueles olhos vigorosos, negros e arrebatadores, começam a se desnudar transformando-se em um "cinza tristonho", nem mesmo a energia de uma nova paixão era capaz de driblar o sentimento intenso da perda "a gota já escorrida no vidro da janela" (COUTO, Ibid.)

Revista Leitura V.2 no 56 - jul/dez 2015 - Número regular - Autor/a: Janaina Santos Silva Soggia p. $88-102$. 


\section{2 - Entre lamentos e rumores}

Quis morrer de ciúmes, quase enlouqueci

Mas depois, como era de costume, obedeci

Chico Buarque

A quarta parte da narrativa, intitulada Morrer de ciúmes, retrata o novo convívio de Rosa com Adélia, quando a nova namorada, tomada de certo ciúmes, começa a questionar Rosa a, finalmente, ir buscar seus pertences em sua antiga casa.

João Rosa não o faz por medo e, até, por sabedoria, pois Clarice estava visivelmente abalada com a separação e fazia questão de deixar isso claro a todos com quem se deparasse. Em contrapartida, exibia um olhar firme e confiante:

Clarice estava um farrapo e queria que o mundo soubesse disso. Amigos lhe traziam relatos do seu deplorável estado. Tinham cruzado com ela na rua: estranhamente a mulher exibia um olhar firme, confiante, de estima quase masculina. (COUTO, 2010, p. 201)

Inicia-se, nesse momento da história, uma troca/inversão de papéis entre Rosa e Clarice: mesmo sofrendo intensa dor, inventando um luto por sua separação, depois, inventando loucura e difamando o ex-marido, Clarice mostrava-se fortalecida por meio de seu olhar. Olhar que sustentava resolutamente a tudo e a todos.

$\mathrm{Na}$ canção buarquiana, a voz feminina entoa "Quis morrer de ciúmes, quase enlouqueci”, aspecto atentamente recuperado pelo autor moçambicano, Mia Couto, em sua recriação literária:

Somados danos e desenganos, os vizinhos entenderam: Clarice estava ensaiando o seu próprio fim. Faltava-lhe apenas um final. Esse desfecho parecia estar chegando: ela queria morrer de ciúme. Já que não viveria de coração, morreria vítima dessa paixão às avessas que é o ciúme. Cantarolava como se rezasse:

- Ó pedaço sem mim... (COUTO, 2010, 202).

Clarice como na canção buarquiana, de certa forma obedece ao mando de seu exmarido e segue seu caminhar, tentando recuperar sua força e dignidade. Na canção "Mas depois como era de costume, odebeci”. Já no conto:

Revista Leitura V.2 no 56 - jul/dez 2015 - Número regular - Autor/a: Janaina Santos Silva Soggia p. $88-102$. 
(...) há muito que já não vivia assim tanto. Viúva sem morte, louca sem insanidade, Clarice se passeava, inventada rainha, entre lamentos e rumores. Ironia sem destino: João Rosa, enquanto vigente marido, sempre a tornara inexistente; agora, a ausência dele era nela a única coisa visível (COUTO, 2010, p. 202).

Na quinta parte da narrativa, chamada A furtada lágrima, João Rosa ministra uma palestra sobre economia global e, ao término, vai ter com Adélia. Toda orgulhosa, a namorada o parabeniza pelo trabalho. Adélia atesta ter visto o namorado se emocionar com a ovação dos aplausos, quase a ponto de chorar. João Rosa o nega e afirma "tinha sido uma lágrima ilegítima, uma aguinha técnica sem história" (COUTO, 2010, p. 203).

$\mathrm{O}$ conflito maior se instaura quando João Rosa afirma ter ministrado a palestra com os olhos somente na namorada, e diz "Pois eu lhe digo, meu amor, a sala estava toda Clarice... Perdão, queria dizer: a sala estava toda claríssima" (COUTO, 2010. p. 204).

Esse ato falho desestabiliza por completo João Rosa que, finalmente, deixa vir à tona o choro e a dor por meses contidos: "Paralisado, João Rosa notou que, em redor, as coisas perdiam o foco. Esfregou os olhos e sentiu os dedos humedecerem. Não havia dúvida: ele chorava copiosamente. Como apenas viu as mulheres fazerem" (COUTO, 2010, p. 204). João Rosa que sempre fizera suas namoradas sofrerem, de repente, se vê sofrendo e chorando por amor.

Na sexta parte, intitulada Um reflexo de mar, João Rosa ao chegar em seu escritório é interpelado por sua secretária, que cuidadosamente, relata ver algo de diferente em seus olhos. Ela diz: "Não é por nada, doutor, mas os seus olhos têm uns reflexos claros, quase azuis" (COUTO, 2010, p. 204).

Os olhos de Rosa que de tão pretos e vigorosos começam a ser desnudados diante do enfrentamento de sua perda, nesse momento "era como se do fundo do olhar uns outros olhos espreitassem. Na verdade, flutuava em seu rosto uma aura que ele nunca dera conta antes" (COUTO, 2010, p. 205). João Rosa, paulatinamente, se transforma e o mundo externo enxerga essa mudança pelo desnudamento de seu olhar.

\section{3 - O dilema do porvir}

Revista Leitura V.2 no 56 - jul/dez 2015 - Número regular - Autor/a: Janaina Santos Silva Soggia p. $88-102$. 
Na sétima parte, O telefonema da mãe, João Rosa recebe um telefonema de sua mãe e a ela relata a sua separação. Para sua surpresa, a mãe atesta que não existe separação, ele não tinha se separado, em verdade, de Clarice, assim como ela nunca havia se separado do marido, mesmo diante da morte. Nesse ponto da narrativa, Adélia atesta que João e a mãe têm os mesmos olhos: "Os mesmos olhos, escuros, profundos, determinados" (COUTO, 2010, p. 206). No entanto, era Clarice quem o conhecia em profundidade e enxergava além da superfície de João: “A ex-mulher reconhecia semelhanças bem mais profundas entre mãe e filho: afinal, nenhum deles aprendera a amar" (COUTO, 2010, p. 207).

Nesse entremeio, João dialoga com Adélia que continua a arguí-lo quanto a ir buscar suas coisas, em caso contrário, ela mesma o faria. É quando João Rosa começa a anunciar o real motivo de seu medo - o de Clarice vislumbrar a verdadeira face da dor do ex-marido:

Mas Adélia não entende, insiste o homem. Clarice quer desfechar nele um remorso como quem dedica um impossível beijo. O prazer dela é vê-lo convertido em gota de chuva, cicatriz de luz e sentir que ele escoa em lágrima e deságua no nada (COUTO, 2010, p. 206-207).

Na oitava parte, À espera de não mais esperar, Clarice vive sozinha o auge de sua dor: ter de arrumar os pertences do ex-marido, concretizando o fim de sua relação. A esperança última aniquilada. Para aliviar sua dor, pensa em beber "Por um simples gargalo de garrafa podem escoar rios de angústia. Há quem busque na bebida ser um outro. Ela não. $\mathrm{Na}$ embriaguez, quem sabe, talvez ela pudesse simplesmente deixar de ser" (COUTO, 2010, p. 208).

Nesse momento, Clarice fica às voltas com a garrafa e relembra João:

No fundo, ela não queria beber. Ela queria ser bebida. Queria ser tragada até a última gota. Ela queria que a ausência de Rosa lhe viesse molhar a boca, devorar-lhe os beijos que foram dele, lamber-lhe nos seios as marcas que João Rosa semear. (COUTO, 2010, p. 208).

Após uma noite de sono entrecortado, Clarice vive um momento epifânico, quando vai até o espelho e se depara com outro eu: "Adormece para acordar de madrugada com a noite pegada às pálpebras. Olha-se no espelho e, espanto dos espantos, não reconhece os 
olhos que a contemplam, escuros e frios como um lago morto. 'João?'” (COUTO, 2010, p. 208).

Nesse momento de sublime alteridade, Clarice estranha-se ao ver em si o olhar enegrecido e frio de João. Estabelece-se, nesse ponto da narrativa, a troca efetiva de papéis. De um lado, João enfraquecendo-se e desnudando-se diante da dor. De outro lado, Clarice, fortalecendo-se e recriando-se a partir da experiência da perda irresoluta.

\section{4 - O enfrentamento iminente}

Quando talvez me quiser rever Já vai me encontrar refeita, pode crer Olhos nos olhos quero ver o que você faz. Ao sentir que sem você eu passo bem demais

Chico Buarque

$\mathrm{Na}$ nona parte da narrativa, intitulada A primeira visita, ocorre o primeiro enfrentamento de João e Clarice. João tenta mascarar sua demora, mas Clarice o desarticula deixando claro saber que ele rondava a casa sem coragem de entrar. Nesse diálogo rígido e inóspito, Clarice exige que João não a chame mais pelo nome e, sim, de "ex-amor". Faz isso porque "O nome é uma luz que um coração acende. E Clarice queria ficar no escuro, desluada, para não enxergar a sua própria existência” (COUTO, 2010. p. 209).

Clarice atesta, assim como sua ex-sogra, que o sentimento de João não havia terminado, uma vez que não existe a possibilidade de um ex-amor, posto que amar é infinito.

Nesse confronto, uma única coisa inquieta João, a firmeza fria do olhar de Clarice. Por fora, ela aparecia em frangalhos, entretanto, seu olhar era imponente: "João Rosa não acreditava no que escutava. Menos ainda no que enxergava: os olhos dela não espelham tristeza nem saudade" (COUTO, 2010, p. 210).

Caminhando para o fim da trama, na décima parte, Livros e Colírios, João Rosa ao voltar desolado de seu encontro com Clarice, é questionado pela namorada enciumada por ter trazido somente suas roupas, deixando o principal em sua antiga casa, seus livros. Adélia fita-o e vê em seus olhos um vermelho alarmante:

- Os seus olhos...

- O que é que há com eles?

Revista Leitura V.2 no 56 - jul/dez 2015 - Número regular - Autor/a: Janaina Santos Silva Soggia p. $88-102$. 
- Vá passar um colírio. Nunca os vi tão vermelhos.

(...) Era nos livros onde ele mais tinha vivido, onde deixara o olhar enrolado, os dedos passeados, a alma gravada (COUTO, 2010, p. 211).

O fato de João Rosa ter deixado seus livros para um enfrentamento final remete à prerrogativa de que nem ele, nem Clarice estariam efetivamente prontos para o desenlace total.

\section{5 - Momento epifânico: a transformação de Clarice}

E que venho até remoçando

Me pego cantando

Sem mais nem porque

E tantas águas rolaram

Quantos homens me amaram

Bem mais e melhor que você

Quando talvez precisar de mim

'Cê sabe que a casa é sempre sua, venha sim

Chico Buarque

Na penúltima parte da narrativa, O eco da voz, Clarice vive um momento de epifania ao rememorar a voz de seu pai contando uma antiga história que falava sobre uma mulher que só tinha começado a ter filhos depois de morta. No relato, o pai de Clarice contava que, a cada nove meses, o coveiro ouvia um choro vindo sempre de uma mesma campa, e ao escavar o túmulo, não obstante, encontrava um recém-nascido. Assim o coveiro o fez dezenas de vezes. Acolhia a cada novo rebento e afundava-se em pobreza para poder criá-los. Até que um dia, o homem decide pavimentar a campa para pôr fim àquele sofrimento. Sua mulher, no entanto, o alerta "o ventre dessa mulher não falece porque esse ventre é a própria Terra, toda inteira" (COUTO, 2010, p. 213).

A lembrança dessa narrativa lendária, ecoada pela memória de seu pai, traz uma revelação à Clarice: "Ela teria que nascer de si mesma, superar a cinza, rasgar na parede da angústia a janela de um novo dia" (COUTO, 2010, p. 213).

E assim o fez, superou a dor da perda de João, e inventou-se a partir de Adélia. "Foi ao espelho e se fez bonita. Foi ao velho baú e se fez vaidosa. Foi ao fundo de si e se fez mulher" (COUTO, 2010, p. 213). 
Ocorre, aqui, um dialogismo evidente entre canção e narrativa literária, no qual as duas personagens femininas, tal como uma fênix, renascem das cinzas e recomeçam o caminhar.

\section{6 - Desfecho: O desnude do olhar}

Olhos nos olhos, quero ver o que você diz Quero ver como suporta me ver tão feliz

Chico Buarque

Na última parte do conto, que remonta ao título da canção buarquiana, Olhos nos olhos, ocorre o enfrentamento fatídico entre João Rosa e Clarice, bem como uma evidente inversão de papéis, traduzida na troca, literal, de seus olhares.

No conto, João Rosa, chega à casa de Clarice para, enfim, buscar seus mais preciosos pertences, seus livros, e a vê sair "adolescente e dona de si mesma como se a rua fosse seu natural território" (COUTO, 2010, p. 214). João até tenta demovê-la, mas Clarice sente uma urgência que "só pode ter quem se esqueceu de viver".

Nesse momento, hipotexto e hipertexto se cruzam, a canção buarquiana, de um lado, questiona: "Olhos nos olhos quero ver o que você diz? Quero ver como suporta me ver tão feliz" (BUARQUE, 1976). Do outro lado, a recriação literária responde: "Então, olhos nos olhos, se deu o impensável. João Rosa encartado caçador de mulheres, não foi capaz de enfrentar Clarice. Rosto baixo, pálpebras tremeluzentes, em véspera de lágrima" (COUTO, 2010, p. 214).

João Rosa não suporta a dor de ver a superação de Clarice frente ao desenlace, ele a encontra como entoa a canção buarquiana: "Quando talvez me quiser rever, já vai me encontrar refeita, pode crer".

Em meio ao desespero da perda da amada, vendo-a abrir-se para uma nova vida, João Rosa momentaneamente cega: 'Clarice, volte... Volte, eu não estou a ver'. O tom era de desespero. Ela parou, deu meia-volta e atravessou, de volta, a estrada. 'Eu estou cego, Clarice!"” (COUTO, 2010, p. 214).

E é na fala final de Clarice que o leitor é capaz de vislumbrar o desnudamento completo dos olhos de João frente à sua perda:

- Você apenas está chorando, meu querido.

- Chorando, eu?

Revista Leitura V.2 no 56 - jul/dez 2015 - Número regular - Autor/a: Janaina Santos Silva Soggia p. $88-102$. 
- Eu sei. Porque esses, no seu rosto, são os meus olhos. E lágrimas que não eram suas desceram como gotas de chuva em vidro de janela (COUTO, 2010, p. 214-215).

Aqueles olhos "negros, de confiança absoluta", apresentados no início da narrativa, haviam sido desnudados e enfraquecidos, a paixão finalmente havia escoado feito "um fio de chuva em vidro de janela" (COUTO, 2010, p. 197).

\section{Considerações finais}

A canção que serviu de base para o corpus desta análise, Olhos nos olhos (1976), foi composta por Chico Buarque e presenteada à cantora Maria Bethânia, por meio de quem disparou nas rádios e tornou-se amplamente conhecida.

A interpretação singular de Bethânia transmite todo o apelo emotivo da voz feminina que sofre a dor da perda de seu grande amor. Tanto na letra, como na interpretação de Bethânia, é possível vislumbrar o caminhar de recomeço desta voz que renasceu mulher, dona de si e fortalecida.

Esse mesmo percurso é retomado pelo escritor moçambicano, Mia Couto, ao transpor para a literatura a conhecida canção brasileira. No conto, o autor se apropria de outros recursos para elaborar um novo original perante o passado. Situa uma tríade amorosa, nomeia as personagens e cria uma trama de enlace e desenlace entre João Rosa, Clarice e Adélia.

Em função do jogo textual presentificado no próprio título de ambas as mídias (de Olhos nos olhos para Olhos nus: olhos), o leitor já entra no texto sob uma perspectiva diferente. A transposição midiática propõe uma nova chave ao apresentar o adjetivo "nus" em lugar da contração "nos". De modo que além do enfrentamento, há o prenúncio do desnudamento do olhar.

Evidencia-se, na análise da obra literária, que esse desnudamento se dá pela transformação dos olhos das duas personagens centrais, João Rosa e Clarice. De um lado, o vigoroso João enfraquece paulatinamente à medida que seus olhos vão se desnudando/despindo: de um negro vibrante, passando pelo cinza, azul, vermelho, até cegar momentaneamente. Em contrapartida, Clarice, mesmo em frangalhos, louca de ciúme, fragmentada, perdida e só, fortalece-se e renasce de si mesma.

A obra literária não apenas dialoga com a canção, mas supera-a e recria-se a partir dela, podendo, com isso, ser reconfigurada como uma tradução intersemiótica da composição buarquiana.

\section{Referências Bibliográficas}

AMORIM, Marcel Álvaro de. Da tradução intersemiótica à teoria da adaptação intercultural: estado de arte e perspectivas futuras. Itinerários. Araraquara: UNESP, n. 36, jan/jun. 2013

BRESSANE, Ronaldo (org). Olhos nus: olhos. Essa história está diferente - Dez contos para canções de Chico Buarque. São Paulo: Companhia das letras, 2010. 
DARIN, Leila. As múltiplas faces de um roteiro: O piano. Tradução em Revista, 19, 2015.2 .

FARIA, Ângela Beatriz de Carvalho. "A paixão é um fio de chuva em vidro de janela: 'Olhos nus: olhos', de Mia Couto e 'Olhos nos olhos', de Chico Buarque'. Mulemba, no 3, UFRJ. Rio de Janeiro: 2010.

Disponível em: http://setorlitafrica.letras.ufrj.br/mulemba/artigo.php?art=artigo 3 4.php. Acesso em 22 de maio de 2016.

HOLlANDA, Chico Buarque. Meu caro amigo. 1976 (C) Marola Edições Musicais

JAKOBSON, Roman. Aspectos linguísticos da tradução. In: Linguística e Comunicação. Tradução de Izidoro Blikstein e José Paulo Paes. São Paulo: Cultrix, 1969.

PERRONE-MOYSÉS, Leyla. Literatura comparada. Intertexto e Antropofagia. Flores da escrivaninha. São Paulo: Companhia das Letras, 1990.

STAM, Robert. A literatura através do cinema - Realismo, Magia e a Arte da Adaptação. Tradução de Marie-Anne Kremer. UFMG, 2008.

STAM, Robert. Teoria e prática da adaptação: da fidelidade à intertextualidade. Ilha do Desterro. Florianópolis, no 51, p. 019-053, jul/dez. 2006.

Revista Leitura V.2 no 56 - jul/dez 2015 - Número regular - Autor/a: Janaina Santos Silva Soggia p. $88-102$. 